\title{
Effect of Nadi Shuddhi Pranayama, Kati Chakrasana and Vakrasana on Depression and Glycemic Control in Type 2 Diabetes Mellitus
}

\author{
Raja D, Deepthi Merin Raju, Indu TH, Sruthy KV, Jayakumar C, Ponnusankar S* \\ Department of Pharmacy Practice, JSS College of Pharmacy, PB No: 20, Rocklands, Udhagamandalam, JSS University, Mysore, Karnataka, INDIA
}

\begin{abstract}
Introduction: Diabetes mellitus (DM) is a predominant source of morbidity in India. The incidence of depression is found to be increased among type 2 DM patients that makes the glycemic control as an exhaustive task and also leads to increasing the risk of diabetes induced complications. Aim: The present study aimed at studying the effect of three yoga on depression and glycemic control in type 2 DM patients. Methods: Nadi Shuddhi Pranayama, Kati Chakrasana and Vakrasana were taught to the recruited participants and clinical characteristic were measured at baseline, visit 1 and visit 2. Results: The mean FBS, PPBS and RBS values of the participants during the two visits were found to be decreased from $131.33 \pm 12.89$ to $122.33 \pm 10.63(p<0.0001), 183.3 \pm 28.02$ to $167.11 \pm 13.95(p=0.0052)$ and $181.81 \pm 20.8$ to $169.22 \pm 21.79(p=0.0050)$ respectively. The HAM D score of SIGH D tool from baseline to visit 2 was found to be reduced from 9 to 3.44 ( $p<0.0001)$. Conclusion: The study showed the evidence of
\end{abstract}

the effectiveness of yoga in the management of depression and glycemic control in type 2 diabetes mellitus patients

Key words: Nadi shuddhi pranayama, Kati chakrasana, Vakrasana, Depression, Yoga, Type 2 diabetes mellitus.

Correspondence

Dr Ponnusankar S, Professor and Head, Department of Pharmacy Practice, JSS College of Pharmacy, PB No: 20, Rocklands, Udhagamandalam, JSS University, Mysore, Karnataka, INDIA.

Phone: +919489613428

Email: ponnusankarsivas@gmail.com

DOI: 10.5530/jyp.2018.10.44

\section{INTRODUCTION}

Diabetes mellitus (DM) is a predominant source of morbidity in India. World Health Organization (WHO) reports that the nation holds the largest number of diabetes patients and can be termed as diabetic capital of the world. ${ }^{1,2}$ Recently the incidence of depression is found to be increased among type 2 DM. ${ }^{3}$ Depression in the DM further decreases the quality of life of the patients, makes the glycemic control an exhaustive task and leads to increasing the risk of diabetes induced complications. ${ }^{3,4}$ Furthermore, the detection and management of depression goes unattended many times. Thus, the presence of depression among diabetes patients is a major concern and requires immediate strategies to overcome.

Yoga is a moderate non-invasive physical activity that helps in attaining balanced breathing patterns. This supplies sufficient oxygen to cells so that cellular respiration increased. Subsequently there might be an increase in the release of 'feel good hormones' such as serotonin leading to balanced metabolism and calmness of mind, and alleviation of depression. The regular practice of yoga thus expected to provide excellent support in stress management. ${ }^{5}$

Yoga also helps in modulating the sympathetic activity and it may even control the endocrine secretions released during stress. ${ }^{5}$ The impact of yoga in controlling type 2 diabetes mellitus has been a recent study interest. Such results shown a significant effect in regulating the body functions, improvement in glycemic control and reducing the side effects to patients already taking anti diabetic medications. ${ }^{6,78}$ However, there are no reports on the effectiveness of yoga on depression among type $2 \mathrm{DM}$ patients. Hence, the present study was focused to study the effect of yoga on depression and glycemic control in type $2 \mathrm{DM}$ patients.

\section{METHODS}

This is a prospective open label interventional study conducted during September 2015 to March 2016 at Government District Headquarters hospital, Ooty. The study was approved by Institutional Review Board, JSS College of Pharmacy, Ooty (JSSCP/DPP/IRB/007/2015-16). The type 2 diabetes mellitus patients age above 18 years with depression, determined with Hamilton Depression Rating Scale (HAM-D) were included in the study. Exclusion criteria include pregnancy, type 1 diabetes mellitus, and type 2 diabetes mellitus with micro or macro vascular complications, renal and hepatic dysfunctions. Study details were explained in person to the patients and written informed consent form was obtained. Subjects who met the inclusion criteria and who were willing to give informed consent form were recruited for the study.

The recruited patients were given yoga training on $30^{\text {th }}$ and $31^{\text {st }}$ January 2016 at Drug Information Center, Clinical Pharmacy Services Department, Government District Headquarters Hospital, Udhagamandalam. The yoga classes were taken by yoga trainers from S -VYASA University, Bangalore. Nadi Shuddhi Pranayama, Kati Chakrasana and Vakrasana were taught to the recruited participants. These yoga asanas were selected based upon their beneficial role in diabetes, depression and general wellbeing; also, they are simple to perform and do not require any yoga attire. In addition, these yoga asanas were simple to the extent that it can be performed by both men and women over a wide range of age.

The subjects along with their regular anti diabetic medications were asked to perform yoga in the following order viz Kati Chakrasana 6 to 7 rounds on each side of the body, Vakrasana 2-3 times on each side of the body for 2 minutes and Nadi Shuddhi Pranayama 5 to 7 rounds in one sittings for duration of 2 to 20 seconds. The subjects were followed up over telephone for their regular yoga practice. 
Patients' data including demographics, past medical and medication history, present medications, biomedical test results were collected in a structured data collection form. The clinical characteristics of the participants such as stress index, SIGH D score, FBS (Fasting blood sugar), PPBS (post prandial blood sugar), RBS (Random blood sugar), LDL (Low density lipoproteins), HDL (High density lipoproteins), BMI (body mass index), pulse, NN50 (number of pairs of successive NN (R-R) intervals that differ by more than $50 \mathrm{~ms}$ ), SDNN (standard deviation of the NN (R-R) intervals), RMSSD (Root mean square of the successive differences) and Heart rate variability (HRV)were monitored at baseline, visit 1 (after 21 days) and visit 2 (after 42 days).

Statistics: Repeated measure one-way ANOVA followed by Dunnett's multiple comparisons test was performed using GraphPad Prism version 6.00 for windows, Graphpad Software, La Jolla California USA, www. graphpad.com.

\section{RESULTS AND DISCUSSIONS}

A total of 72 type $2 \mathrm{DM}$ patients were screened, among them 17 patients were found to have depression. The prevalence of depression in the study site was found to be $23.61 \%$ (mild grade of severity). Through this study, $47.05 \%$ of them came to know that they are depressed. This indicates the necessity to administer SIGH D in all recently diagnosed type 2 diabetes and pre-diabetes subjects to find out depression among them, if any and treatment can be initiated at the earliest.

A total of 12 subjects were eligible to attend the yoga classes, out of them 9 completed the study (75\%). One-fourth of the study participants were not able to practice yoga regularly due to either their social commitment or lack of time. Similar results were even reported by Raja et al for regular exercise in type 2 DM. ${ }^{9}$ The scheme of the study is shown in Figure 1.

Majority (67\%) of the study participants were male. The gender plays a major role in adherence to yoga daily. The dropout among the women participants was found to be more compared to men (25\%). Imparting awareness on importance of yoga in participants can theoretically improve the daily yoga practice and reduce drop outs; however, the success is to be demonstrated in further studies.

The mean age of the study participants was found to be $51.56 \pm 7.23$ and the mean duration of diabetes was found to be $6.78 \pm 4.68$. The onset age of diabetes is seeming to decline and a considerable portion of younger people in the population is affected with diabetes presently. The reason put forward are physical inactivity, excessive calorie intake leading to obesity and genetic factors. ${ }^{10}$

The clinical characteristics of the participants observed at visit 1 (after 21 days) and visit 2 (after 42 days) was shown in Table 1.

The mean FBS, PPBS and RBS values of the participants during the two visits were found to be reduced from $131.33 \pm 12.89$ to $122.33 \pm 10.63$ ( $\mathrm{p}<0.0001), 183.3 \pm 28.02$ to $167.11 \pm 13.95$ ( $\mathrm{p}=0.0052)$ and $181.81 \pm 20.8$ to $169.22 \pm 21.79(\mathrm{p}=0.0050)$ respectively (Figure 2$)$. Dunnet multiple comparison test was used to estimate the variation in sugar levels from base lines. From the post hoc test, the FBS values was shown a mean difference of 10.44 (95\% CI: 5.86 to 15.03 ) and 19.56 (95\% CI: 11.26 to 27.86) from baseline to visit 1 and 2 respectively. The RBS values from baseline to visit 1 and 2 were shown a mean difference of 30.44 (95\% CI: 3.094 to 57.80 ) and 43.11 (95\% CI: 14.53 to71.69). Similarly, PPBS values was shown a mean difference of 21.78 (95\% CI: 7.69 to 35.86 ) from baseline to visit 2 . The significant differences in RBS and FBS were shown at week 3 and week 6, whereas the PPBS shown significant difference at 6 weeks from baseline. Daily yoga practice provides a massage to abdominal organs, rejuvenate the pancreas cells and influence the glycemic control. ${ }^{11}$ A study done by S. Amita et al (2009) had shown that yoga-nidra practiced for 30 minutes daily up to 90 days resulted in fall

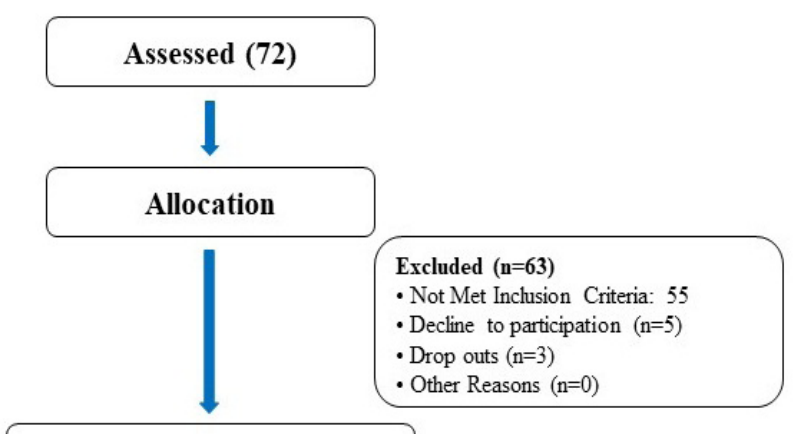

Intervention group $(\mathrm{n}=09)$

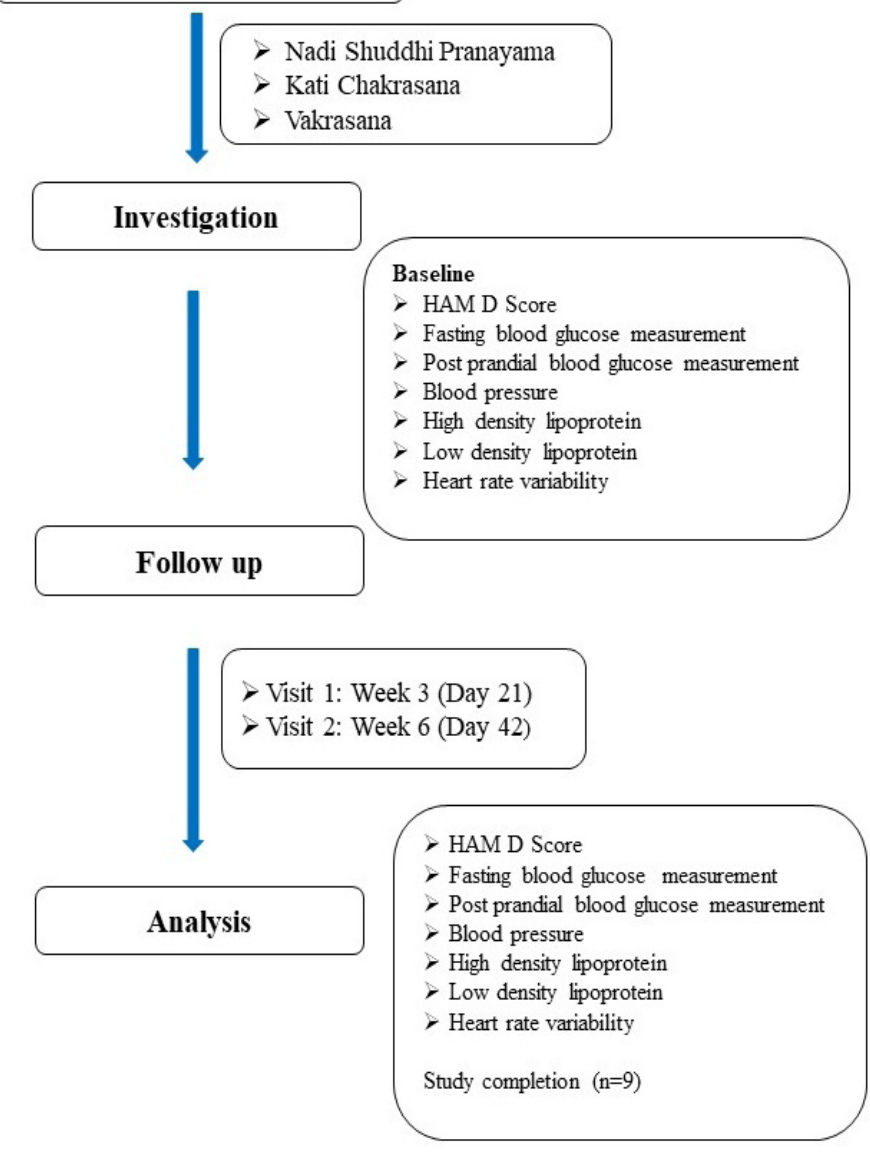

Figure 1: The scheme of the study.

in mean blood glucose level and symptoms associated with diabetes. ${ }^{[12]}$ However, the results from the present study revealed that a regular practice of the yoga can significantly reduce the blood glucose levels even from a period of 6 weeks. The yoga practices usually involve physical exercises combined with regulated breath, have the ability on glycemic control and improve quality of life. ${ }^{12,13}$

The SIGH D values from baseline to visit 1 and visit 2 were found to be reduced from 9 to 5 and $3.44(\mathrm{p}<0.0001)$ with a mean difference of 4 (95\% CI: 2.66 to 5.33 ) and 5 (95\% CI: 4.36 to 6.74 ). Similarly, from baseline to visit 2 , the stress index values are reduced from 36.56 to 17.11 ( $\mathrm{p}=0.1562)$. All the subjects showed significant improvement in various symptoms of depression. They also experienced yoga as feasible intervention to perform in day today life as per one's convenience. These 

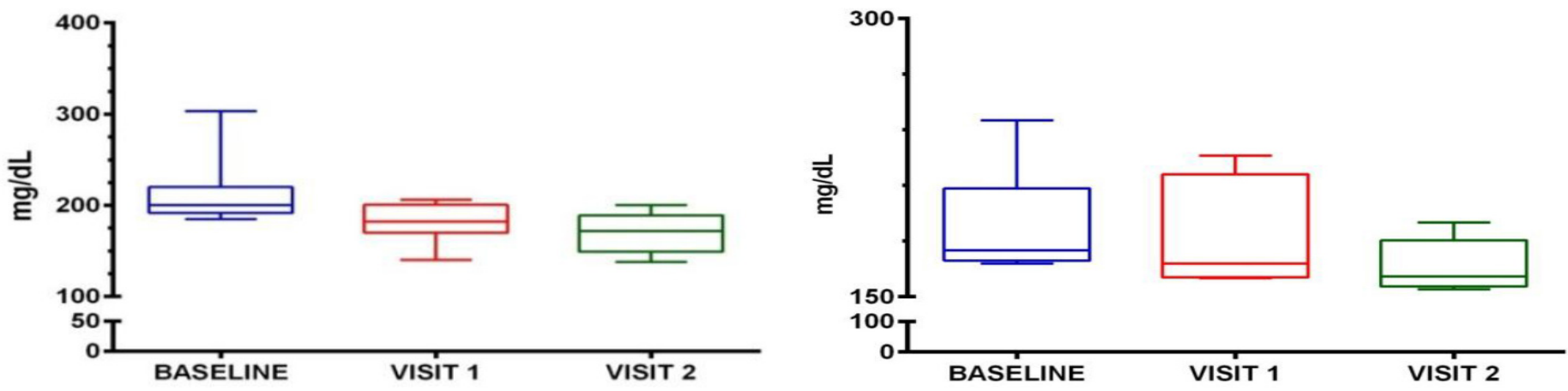

Fig 2A: Effect of yoga on RBS

Fig 2C: Effect of yoga on PPBS
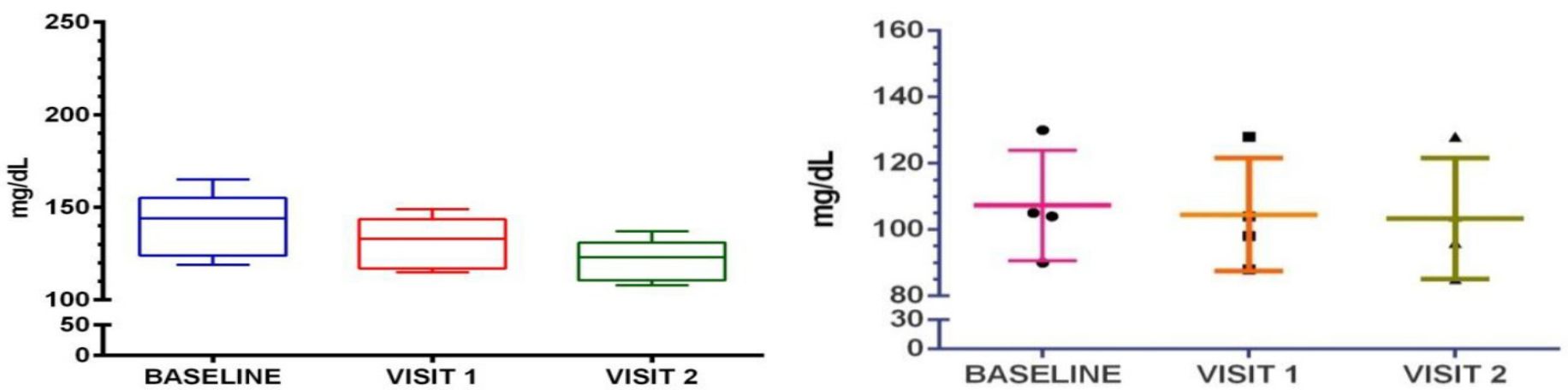

Fig 2B: Effect of yoga on FBS

Fig 2D: Effect of yoga on LDL

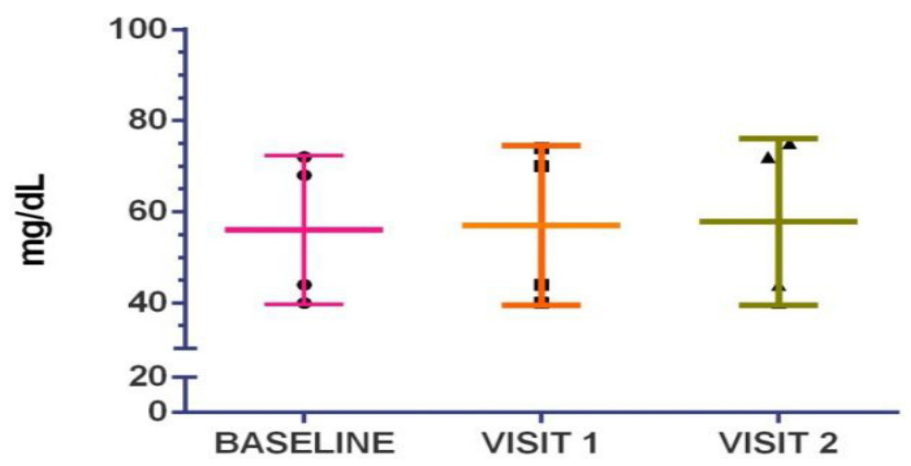

Fig 2E: Effect of yoga on HDL

Figure 2: Effect of yoga on glucose and cholesterol levels (Group values).

$\mathrm{RBS}=$ random blood sugar, FBS=fasting blood sugar, $\mathrm{PPBS}=$ post prandial blood sugar, $\mathrm{LDL}=$ low density lipoproteins, $\mathrm{HDL}=\mathrm{high}$ density lipoproteins

results are supported by the evidences published by Sharma et al and David Shapiro et al. ${ }^{14,15}$ The regularized breathing during yoga helps to calm the mind relieving stress. ${ }^{16}$

The mean LDL and HDL values were found to be changed from $104.5 \pm 17.01$ to $103.25 \pm 18.25$ ( $\mathrm{p}=0.1347$ ) and $57.01 \pm 17.47$ to $57.75 \pm 18.30$ $(\mathrm{p}=0.1880)$. The visceral adiposity is responsible for the excessive release of TNF-alpha, interleukin-6 and visfatin, which may lead to insulin resistance. ${ }^{17}$ It is well proven that yoga can decrease the excess fat deposition, reduce waist circumferences and body weight. ${ }^{18,19}$ The systematic relaxation practices through the pranayama techniques reduce the adrenergic activity and thereby may reduce the stress. ${ }^{20}$ These effects can have favorable results in the lipid levels as the stress levels have a direct relationship with the cholesterol levels. ${ }^{21}$

The mean BMI of the participants during visit 1 and 2 was found to be same $\left(23.82 \pm \mathrm{Kg} / \mathrm{m}^{2}, \mathrm{p}=0.3388\right)$ and the pulse values changed from $71.89 \pm 10.86$ to $72.56 \pm 1.67(\mathrm{p}=0.9031)$. Few studies have shown that yoga practices have a positive impact on controlling BMI and pulse. ${ }^{19,22,23}$ However no significant difference was found in our study for LDL, HDL, BMI and Pulse.

HRV is a quantitative marker depicting the activity of autonomic nervous system (ANS) related to mental stress, measure of individual differences in regulated emotional response. ${ }^{24}$ Low HRV indicates high sympathetic and low parasympathetic (vagal) autonomic activity and is a predictor of many cardiovascular events and mortality. ${ }^{25}$ A low (RMSSD) value indicates high stress, RMSSD is root mean square of differences between successive rhythm-to-rhythm (RR) intervals. ${ }^{24}$ The mean NN50, SDNN and RMSSD was found to be changed from $45.33 \pm 6.28$ to $39.56 \pm 12.18(\mathrm{p}=0.3060), 423.11$ to $397.78(\mathrm{p}=0.8768)$ and 632.89 to $556.78(\mathrm{p}=0.4206)$ at final visit. The HRV values were found to be changed from 1211.89 to $1357.67(\mathrm{p}=0.2068)$ at visit 2 . The significant mean difference in HRV $(\mathrm{p}<0.05)$ was found from baseline to visit 1 measured by Dunnet multiple comparison test [mean difference: 115.2, 
Table 1: Clinical characteristics of the study participants.

\begin{tabular}{cccc}
\hline Characteristics & Baseline & $\begin{array}{c}\text { Visit 1 } \\
\text { (21 days) }\end{array}$ & $\begin{array}{c}\text { Visit 2 } \\
\text { (42 days) }\end{array}$ \\
\hline BMI, Mean (SD) Kg/m ${ }^{2}$ & & $23.82(1.19)$ & $23.82(1.19)$ \\
FBS, mg/dl Mean (SD) & $23.84(1.16)$ & $131.33(12.89)$ & $122.22(10.63)$ \\
PPBS, mg/dl Mean (SD) & $141.78(16.15)$ & $183.33(28.02)$ & $167.11(13.95)$ \\
RBS, mg/dl Mean (SD) & $188.89(28.97)$ & $181.89(20.80)$ & $169.22(21.79)$ \\
LDL, mg/dl Mean (SD) & $212.33(36.6)$ & $104.5(17.01)$ & $103.25(18.25)$ \\
HDL, mg/dl Mean (SD) & $107.25(16.64)$ & $57.01(17.47)$ & $57.75(18.30)$ \\
Ham D Score (SD) & $56.08(16.33)$ & $5(2.29)$ & $3.44(1.33)$ \\
Pulse, bpm Mean (SD) & $9(1.32)$ & $71.44(4.72)$ & $72.56(1.67)$ \\
NN50 Mean (SD) & $71.89(10.06)$ & $41.44(11.49)$ & $39.56(12.18)$ \\
SDNN & $45.33(6.28)$ & 436.67 & 397.78 \\
RMSSD & 423.11 & 776.89 & 556.78 \\
HRV & 632.89 & 1308.67 & 1357.67 \\
STRESS INDEX & 1211.89 & 15.56 & 17.11 \\
\hline
\end{tabular}

BMI=body mass index, FBS=fasting blood sugar, PPBS=post prandial blood sugar, LDL=low density lipoproteins, HDL=high density lipoproteins, Ham D Score=Hamilton Depression Rating Scale, NN50=number of pairs of successive NN (R-R) intervals that differ by more than 50 ms, SDNN=standard deviation of the NN (R-R) intervals, RMSSD=root mean square of the successive differences, HRV=heart rate variability, $\mathrm{SD}=$ standard deviation

95\% CI: -218 to -12.41]. Studies have shown that HRV is a more useful psychophysiological measure than heart rate alone and a single session of hatha yoga can increase HRV acutely. ${ }^{26}$

From the study, it is suggested to have a skilled yoga instructor to design the yoga practices as per the patients' requirements. This may allow individualizing and thereby optimizing the treatment, which in turn maximizes the benefit. ${ }^{27}$

\section{LIMITATIONS}

There was no control group for the study. Also, the adherence of the participants to the yoga practice was done over telephone and not under direct supervision. Being a pilot study, we could recruit only 12 patients and 9 patients completed the study for a period of 6 weeks. These factors can be given due consideration while planning similar studies in the future to establish better perception on the benefits and therapeutic effects of yoga on depression, glycemic control, blood pressure, heart rate variability scores, BMI, LDL and HDL levels.

\section{CONCLUSION}

The prevalence of depression among type 2 diabetes mellitus patients was found to be $23.61 \%$ in the study site. The practice of Nadi Shuddhi Pranayama, Kati Chakrasana and Vakrasana for a period of 6 weeks among the participants showed to alleviate their depression status, FBS, RBS and PPBS levels significantly. The study clearly shows the effectiveness of yoga in the management of depression and glycemic control in type 2 diabetes mellitus patients. Thus, yoga can be used as a valuable tool for diabetic educators for developing suitable strategies for those individuals who express interest in yoga practice for glycemic control and management of depression.

\section{ACKNOWLEDGEMENT}

The authors acknowledge the support provided by the Government district headquarters hospital, Udhagamandalam and wish to thank Dr. B Ragavendraswamy and Dr. B Suresh Babu from S -VYASA
University, Bangalore for their support in conducting yoga classes at Ooty. We thank the Tamilnadu Pharmaceutical Sciences welfare trust, Chennai for extending a scholarship for this study. Lastly, we are much thankful to JSS University for funding "Yoga Praziksana - Yoga for All" program.

\section{CONFLICT OF INTEREST}

Authors have no conflict of interest to declare.

\section{REFERENCES}

1. Mohan V, Sandeep S, Deepa R, Shah B, Varghese C. Epidemiology of type 2 diabetes: Indian scenario. Indian J Med Res. 2007;125(3):217-30.

2. Raja D, Vijayakumar APR, Santhy SD, Kumar KMS, Jayakumar C, Vijayan P. Management of type 2 Diabetes Mellitus: Assessment of the Community Pharmacists' Contribution in selected districts of Tamilnadu state, India. Int J Pharm Sci. 2014;6(2):156-8.

3. Finkelstein EA, Bray JW, Chen H, Larson MJ, Miller K, Tompkins C, et al. Prevalence and costs of major depression among elderly claimants with diabetes. Diabetes Care. 2003:26(2):415-20.

4. Gavard JA, Lustman PJ, Clouse RE. Prevalence of depression in adults with diabetes- An epidemiological evaluation. Diabetes Care. 1993;16(8):1167-78.

5. Parasuraman S, Wen EL, Zhen MK, Hean KC, Sam AT. Exploring the pharmacological and pharmacotherapeutic effects of yoga. Pharmacol Toxicol Biomed Rep. 2016;2(1):6-10

6. Gupta N, Khera S, Vempati RP, Sharma R, Bijlani RL. Effect of yoga-based lifestyle intervention on state and trial anxiety. Indian J Physiol Pharmacol. 2006;50(1):41-7.

7. Sahay BK. Role of yoga in diabetes. J Assoc Physicians India. 2007;55:121-6.

8. Subhash MC, Sendil DK, Kanhere VV, Ragunatha S. Effect of yoga on blood glucose levels in patients with Type 2 Diabetes Mellitus. J Clin Diagn Res. 2015;9(4):CC01-3.

9. Raja D, Venkata Ramana Devi T, Anand Vijaykumar PR. Assessment of exercise barriers in type 2 diabetes patients: A cross sectional study performed at Government District Headquarters hospital, Udhagamandalam, The Nilgiris, Tamil Nadu, India. Int J Pharm Bio Sci. 2014;5(1):706-13.

10. Chapla A, Mruthyunjaya MD, Asha HS, Varghese D, Varshney M, Vasan SK, et al. Maturity onset diabetes of the young in India: a distinctive mutation pattern identified through targeted next- generation sequencing. Clin Endocrinol (Oxf). 2015;82(4):533-42.

11. Balaji PA, Smitha RV, Ali SS. Physiological effects of yogic practices and transcendental meditation in health and disease. N Am J Med Sci. $2012 ; 4(10): 442-8$ 
12. Amita S, Prabhakar S, Manoj I, Harminder S, Pavan T. Effect of yoga - nidra on blood glucose level in diabetic patients. Indian $\mathrm{J}$ Physiol Pharmacol. 2009:53(1):97-101.

13. Jyotsna VP, Joshi A, Ambekar S, Kumar N, Dhawan A, Sreenivas V. Comprehensive yogic breathing program improves quality of life in patients with diabetes. Indian J Endocrinol Metab. 2012;16(3):423-8.

14. Sharma VK, Das S, Mondal S, Goswami U, Gandhi A. Effect of Sahaj Yoga on neuro-cognitive functions in patients suffering from major depression. Indian J Physiol Pharmacol. 2006;50(4):375-83.

15. Shapiro D, Cook IA, Davydov DM, Ottaviani C, Leuchter AF, Abrams M. Yoga as a complementary treatment of depression: effects of traits and moods on treatment outcome. Evid Based Complement Alternat Med. 2007;4(4):493-502.

16. Pilkington K, Kirkwood G, Rampes H, Richardson J. Yoga for depression: the research evidences. J Affect Disord. 2005;89(1):13-24.

17. Guilherme A, Virbasius JV, Puri V, Czech MP. Adipocyte dysfunctions linking obesity to insulin resistance and type 2 diabetes. Nat Rev Mol Cell Biol. 2008; 9(5):367-77.

18. Khatri D, Mathur KC, Gahlot S, Jain S, Agrawal RP. Effect of yoga and meditation on clinical and biochemical parameters of metabolic syndrome. Diabetes Res Clin Pract. 2007;78(3):e9-10

19. Seo DY, Lee S, Figueroa A, Kim HK, Baek YH, Kwak YS, et al. Yoga training improves metabolic parameters in obese boys. Korean $\mathrm{J}$ Physiol Pharmacol. 2012;16(3):175-80.
20. Arora S, Bhattacharjee J. Modulation of immune responses in stress by Yoga. Int J Yoga. 2008;1(2):45-55.

21. Pallav S. Health Impacts of Yoga and Pranayama: A State-of-the-Art Review. Int J Prev Med. 2012;3(7):444-58.

22. Kosuri M, Gumpeny R. Sridhar. Yoga practices in diabetes improves physical and psychological outcome. Metab Syndr Relat Disord. 2009;7(6):515-8.

23. Singh S, Malhotra V, Singh KP, Madhu SV, Tandon OP. Role of yoga in modifying certain cardiovascular functions in type II diabetic patients. J Assoc Physicians India. 2004;52:203-6.

24. Orsila $R$, Virtanen $M$, Luukkaala $T$, Tarvainen $M$, Karjalainen $P_{1}$ Viik J, et al. Perceived mental stress and reactions in heart rate variability-a pilot study among employees of an electronics company. Int J Occup Saf Ergon. 2008;14(3):275-83.

25. Cheema BS, Houridis A, Busch L, Cheema VR, Melville GW, Marshall PW et al. Effect of an office worksite-based yoga program on heart rate variability: outcomes of a randomized controlled trial. BMC Complement Altern Med. 2013;13(1):82.

26. Raghuraj P, Ramakrishnan AG, Nagendra HR, Telles S. Effect of two selected yogic breathing techniques on heart rate variability. Indian J Physiol Pharmacol. 1998;42(4):467-72.

27. Naik D, Thomas N. Yoga- a potential solution for diabetes and metabolic syndrome. Indian J Med Res. 2015;141(6):753-6.

Article History: Submission Date : 06-12-2017 ; Revised Date : 04-01-2018; Acceptance Date : 27-01-2018.

Cite this article: Raja D, Raju DM, Indu TH, Sruthy KV, Jayakumar C, Ponnusankar S. Effect of Nadi Shuddhi Pranayama, Kati Chakrasana and Vakrasana on Depression and Glycemic Control in Type 2 Diabetes Mellitus. J Young Pharm. 2018;10(2):197-201. 